\title{
The Effect of Cobalt Mixing on Pure Copper Mercury Thiocyanate Nonlinear Optical Crystal
}

\author{
B. Vijayabhaskaran ${ }^{1}$, C. Ramachandra Raja ${ }^{2^{*}}$ \\ ${ }^{1}$ Department of Physics, Anjalai Ammal Mahalingam Engineering College, Kovilvenni, India \\ ${ }^{2}$ Department of Physics, Government Arts College (Autonomous), Kumbakonam, India \\ Email: *crraja_phy@yahoo.com
}

Received March 3, 2012; revised April 13, 2012; accepted May 9, 2012

\begin{abstract}
The nonlinear optical crystals of cobalt $\left(\mathrm{Co}^{2+}\right)$ mixed copper mercury thiocyanate have been grown by slow evaporation method using water and ethanol as solvents. The grown crystals have been subjected to different characterization analyses and the results were compared with pure copper mercury thiocyanate crystal (CMTC), which has been already reported. The single crystal X-ray diffraction shows that the addition of metallic impurity does not alter the basic structure of the parent crystal, but increases the cell volume markedly. The presence of functional groups has been identified using FT-IR analysis. Further the grown crystal is characterized by optical transmission analysis and thermal analysis. The thermal stability of the grown crystal is high, compared to pure CMTC crystal. The optical transparency of the grown crystal is studied by UV-Vis-NIR analysis. This study reveals that $\mathrm{Co}^{2+}$ mixed CMTC crystal has wider transparent waveband than pure CMTC crystal. The relative second harmonic generation efficiency of the $\mathrm{Co}^{2+}$ mixed CMTC crystal has been tested by Kurtz-Perry powder technique.
\end{abstract}

Keywords: Crystal Growth; Slow Evaporation Method; X-Ray Technique; FT-IR; Nonlinear Optical Material; Thermal Analysis

\section{Introduction}

Bimetallic thiocyanate complexes of type $\mathrm{AB}(\mathrm{SCN})_{4}$ and their derivatives are much potentially useful among the inorganic systems because all of them contain $-\mathrm{S}=\mathrm{C}=\mathrm{N}$ bridges, which connect $\mathrm{A}$ and $\mathrm{B}$ atoms, forming infinite two dimensional or three dimensional networks. The infinite networks produce a relatively large polarization which induces relatively large macroscopic nonlinearities in the materials [1]. Compared to organic crystals, the inorganic crystals have good physicochemical stabilities and larger second order nonlinearities. Due to these reasons, the inorganic crystals are gaining popularity in the field of nonlinear optics. Inorganic complex crystals have wide range of application in the field of optical disk data storage, laser remote sensing, optical information processing, optical computing, laser driven fusion, colour display and medical diagnostics [2-4]. Some of the doped crystals of the bimetallic thiocyanate complexes are also found to exhibit nonlinear optical properties [5,6]. In the present work an attempt has been made by substituting certain amount of $\mathrm{Hg}^{2+}$ by $\mathrm{Co}^{2+}$ in the already reported crystal copper mercury thiocyanate (CMTC) [7]. The characterization of the new crystal was compared with

\footnotetext{
"Corresponding author.
}

respect to pure CMTC crystal.

\section{Experimental Details}

The synthesis, growth and characterization of pure CMTC crystal has been already reported [7]. According to the above literature, the raw materials were taken in the proper stoichiometric ratios and then dissolved in deionized water and ethanol using the following reaction.

$$
\mathrm{CuCl}_{2}+\mathrm{HgCl}_{2}+4 \mathrm{KSCN} \rightarrow \mathrm{CuHg}(\mathrm{SCN})_{4}+4 \mathrm{KCl}
$$

The solution was then filtered twice to remove any insoluble impurities. Then, the purity of the compound was increased by successive recrystallization processes. By using the slow evaporation technique, large crystals of CMTC were successfully grown from supersaturated solution at a temperature $35^{\circ} \mathrm{C}$ in a constant temperature bath of accuracy $\pm 0.01^{\circ} \mathrm{C}$ [7]. The same procedure was repeated for the growth of $\mathrm{Co}^{2+}$ mixed CMTC crystal by substituting $75 \%$ of $\mathrm{Hg}^{2+}$ by $\mathrm{Co}^{2+}$. Within 22 days many tiny crystals were formed by spontaneous nucleation. After a period of 4 weeks, the grown crystals were harvested and subjected to different characterization methods. Due to the addition of metallic impurity in the pure CMTC crystal, the colour of the crystal is changed from 
clear white to bluish white. The photograph of the grown single crystal is shown in Figure 1.

\section{Characterization Techniques}

The lattice parameters of the grown crystal have been determined from the single crystal X-ray diffraction analysis using Bruker AXS kappa APEX II CCD diffractometer equipped with graphite-monochromated Mo $(\mathrm{K} \alpha)(\lambda=0.7107 \AA)$ radiation. The powder form of $\mathrm{Co}^{2+}$ mixed CMTC was mixed with $\mathrm{KBr}$ to form pellets for obtaining FT-IR spectrum in the mid IR range (400 $4000 \mathrm{~cm}^{-1}$ ) using Perkin-Elmer IFS 66 spectrometer. In the present study, the transmission spectrum of $\mathrm{Co}^{2+}$ mixed CMTC crystal was recorded using Lambda 35 spectrophotometer. The combined thermogravimetric (TG) and differential thermal analysis (DTA) of $\mathrm{Co}^{2+}$ mixed CMTC crystal was recorded in the range from room temperature to $1000^{\circ} \mathrm{C}$ using SDT Q600 V8.3 Build 101, under nitrogen atmosphere, with a heating rate of $20^{\circ} \mathrm{C} /$ $\min$. The second harmonic generation conversion efficiency test has been carried out using modified setup of Kurtz and Perry.

\section{Results and Discussion}

\subsection{Single Crystal XRD}

The observed results indicate that both the pure and $\mathrm{Co}^{2+}$ mixed CMTC crystals belong to monoclinic crystal system. The lattice parameters of pure [7] and cobalt mixed CMTC crystals are given below:

\begin{tabular}{cccccccc}
\hline Crystals & $\mathrm{a}(\AA)$ & $\mathrm{b}(\AA)$ & $\mathrm{c}(\AA)$ & $\alpha$ & $\beta$ & $\gamma$ & $\mathrm{V}\left(\AA^{3}\right)$ \\
\hline Pure CMTC & 11.09 & 4.10 & 11.34 & $90^{\circ}$ & $115.13^{\circ}$ & $90^{\circ}$ & 467 \\
$\begin{array}{c}\text { Cobalt mixed } \\
\text { CMTC }\end{array}$ & 6.14 & 12.18 & 9.04 & $90^{\circ}$ & $104.99^{\circ}$ & $90^{\circ}$ & 653 \\
\hline
\end{tabular}

The variation of lattice parameters and the increase in cell volume are attributed to the incorporation of cobalt in the pure CMTC crystal.

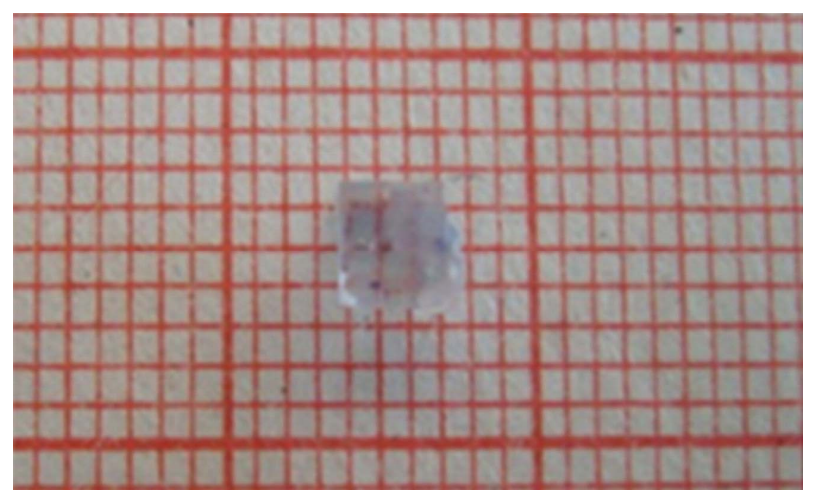

Figure 1. Photograph of $\mathrm{Co}^{2+}$ mixed CMTC crystal.

\subsection{FT-IR Spectral Analysis}

FT-IR (Fourier Transform Infrared) spectroscopy is one of the most reliable methods for identification of functional groups in organic, inorganic and polymeric materials. The recorded spectrum has been compared with the available literatures [8-11]. The FT-IR absorption spectrum of $\mathrm{Co}^{2+}$ mixed CMTC crystals is shown in Figure 2. The comparative study of absorption peaks and their assignments of frequencies are given below:

\begin{tabular}{cccccc}
\hline Crystals & $\begin{array}{c}v(\mathrm{OH}) \\
\left(\mathrm{cm}^{-1}\right)\end{array}$ & $\begin{array}{c}v(\mathrm{CN}) \\
\left(\mathrm{cm}^{-1}\right)\end{array}$ & $\begin{array}{c}v(\mathrm{CN}) \\
\left(\mathrm{cm}^{-1}\right)\end{array}$ & $\begin{array}{c}v(\mathrm{CS}) \\
\left(\mathrm{cm}^{-1}\right)\end{array}$ & $\begin{array}{c}v(\mathrm{SCN}) \\
\left(\mathrm{cm}^{-1}\right)\end{array}$ \\
\hline Pure CMTC & 3543 & 2111 & 1115 & 718 & 618 \\
$\begin{array}{c}\text { Cobalt mixed } \\
\text { CMTC }\end{array}$ & 3423 & 2077 & 1109 & 750 & 620 \\
\hline
\end{tabular}

The symmetric stretching of $\mathrm{OH}$ gives rise to the absorption bands at 3543 and $3423 \mathrm{~cm}^{-1}$. In both the cases $\mathrm{C}-\mathrm{N}$ vibration is observed around 2100 and $1100 \mathrm{~cm}^{-1}$. It is also well known that the peaks at 2111, 2077, 1115 and $1109 \mathrm{~cm}^{-1}$ correspond to $\mathrm{C}-\mathrm{N}$ stretching vibrations. It is well known that the peaks at 718 and $750 \mathrm{~cm}^{-1}$ correspond to C-S stretching vibration and the peaks at 618 and $620 \mathrm{~cm}^{-1}$ correspond to SCN stretching vibration respectively. The differences in the frequencies of functional groups may be due to the addition of cobalt in the pure crystal of CMTC.

\subsection{Optical Transmission Spectral Analysis}

The recorded spectrum is shown in Figure 3. The optical transmission range and transparency cut-off wavelength of $\mathrm{Co}^{2+}$ mixed CMTC crystal have been compared with the reported literature [7] of pure CMTC crystal.

\begin{tabular}{ccc}
\hline Crystals & $\begin{array}{c}\text { UV cut-off } \\
\text { wavelength }(\mathrm{nm})\end{array}$ & $\begin{array}{c}\text { Transparent wave } \\
\text { band region }(\mathrm{nm})\end{array}$ \\
\hline Pure CMTC & 390 & $390-973$ \\
Cobalt mixed CMTC & 245 & $245-1100$ \\
\hline
\end{tabular}

From this analysis, it is understood that the UV cut-off wavelength of $\mathrm{Co}^{2+}$ doped CMTC is low and it has wider transparent wave band compared to pure CMTC crystal. This transparent nature in the UV-Vis-NIR region can be used for various nonlinear optical applications [12].

\subsection{Thermal Analysis}

The recorded TG/DTA curve of $\mathrm{Co}^{2+}$ mixed CMTC crystal is shown in Figure 4. The material exhibits single stage weight loss starting at $360^{\circ} \mathrm{C}$. But below this temperature no weight loss is observed. In DTA analysis, there is a broad endothermic peak at around $345^{\circ} \mathrm{C}$, 


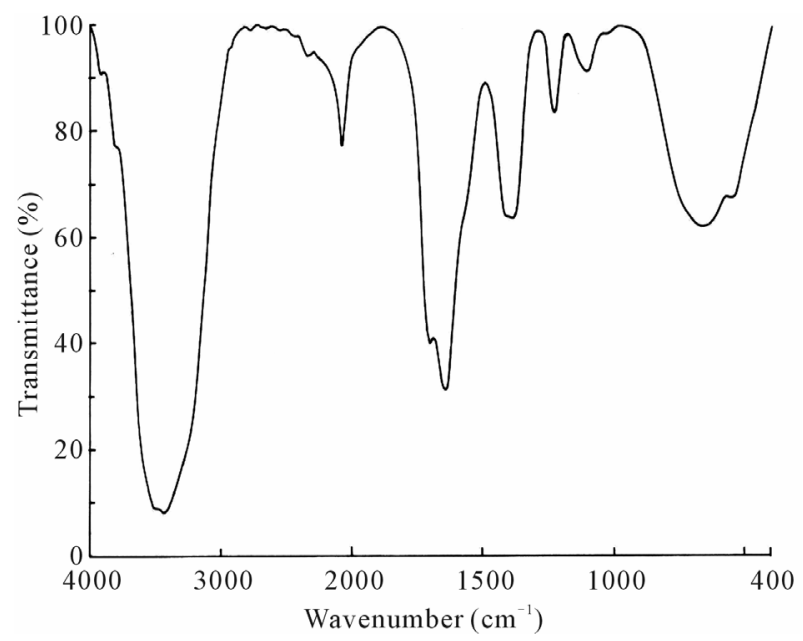

Figure 2. FT-IR spectral pattern of $\mathrm{Co}^{2+}$ mixed CMTC crystal.

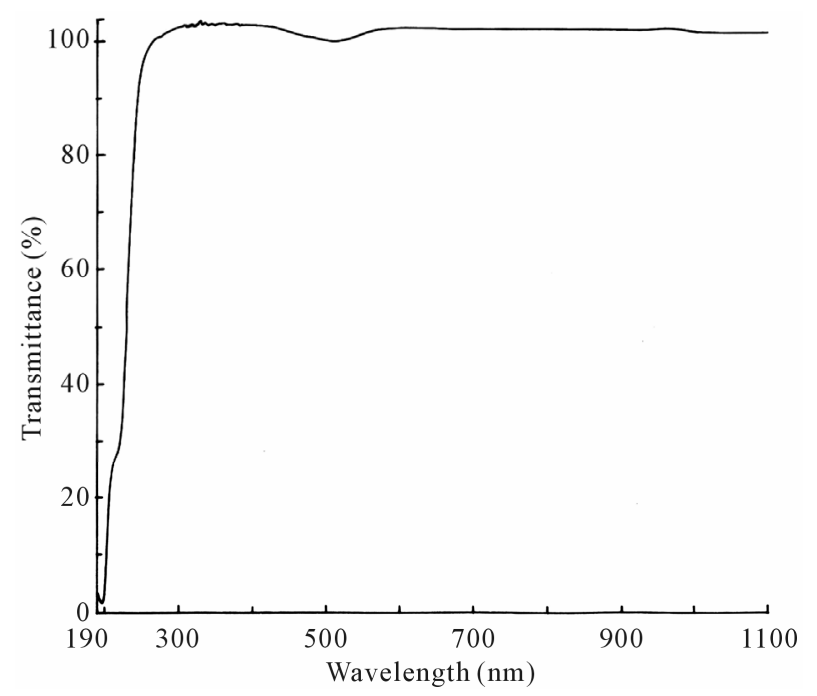

Figure 3. UV-Vis-NIR spectrum of $\mathrm{Co}^{2+}$ mixed CMTC crystal.

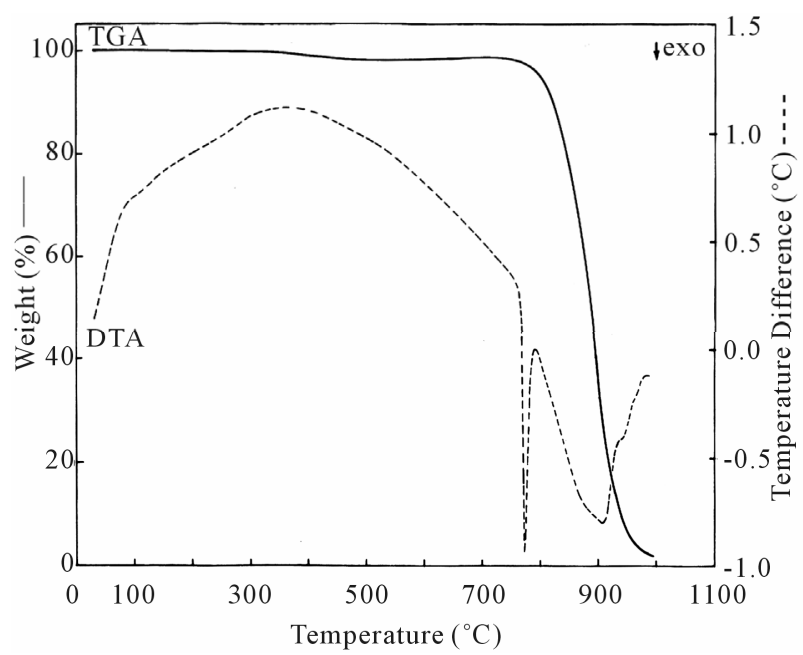

Figure 4. TGA/DTA curves of $\mathrm{Co}^{2+}$ mixed CMTC crystal. which is assigned as the melting point of the specimen, followed by a sharp exothermic peak around $772^{\circ} \mathrm{C}$ which corresponds to the decomposition of $\mathrm{Co}^{2+}$ mixed CMTC compound. It may be worth the mention here that this value coincides well with the recorded TGA value.

\begin{tabular}{ccc}
\hline Crystals & Weight loss starting at & Melting point \\
\hline Pure CMTC & $300^{\circ} \mathrm{C}$ & $253^{\circ} \mathrm{C}$ \\
Cobalt mixed CMTC & $360^{\circ} \mathrm{C}$ & $345^{\circ} \mathrm{C}$ \\
\hline
\end{tabular}

Due to the inclusion of $\mathrm{Co}^{2+}$ in pure CMTC crystal the thermal stability of the material is increased. The observed results are better than that of pure $\mathrm{CuHg}(\mathrm{SCN})_{4}$, $\mathrm{ZnHg}(\mathrm{SCN})_{4}$ and $\left(\mathrm{Cd}(\mathrm{SCN})_{2}(\mathrm{DMSO})_{2}\right)[13,14]$ crystals.

\subsection{Kurtz Powder Technique}

The second harmonic generation conversion efficiency test has been carried out using modified setup of Kurtz and Perry [15] at the Indian Institute of Science, Bangalore. A Q-switched Nd:YAG laser beam of wavelength $1064 \mathrm{~nm}$, with an input power of $4.5 \mathrm{~mJ} /$ pulse, and pulse width of $10 \mathrm{~ns}$ with a repetition rate of $10 \mathrm{~Hz}$ was used. The grown crystals were crushed into a fine powder and then packed in a micro-capillary of uniform bore and exposed to laser radiations. The $532 \mathrm{~nm}$ radiation was collected by a monochromater after separating the 1064 nm pump beam with an infra-red blocking filter. The second harmonic radiation generated by the randomly oriented micro-crystals was focused by a lens and detected by a photomultiplier tube (Hamamatsu R2059). The emission of green light confirms the second harmonic generation. The output power of $\mathrm{Co}^{2+}$ mixed CMTC is $6 \mathrm{mV}$. For the same input the output power of pure CMTC crystal is $4.5 \mathrm{mV}$. It was found that the conversion efficiency of $\mathrm{Co}^{2+}$ mixed CMTC crystal was found to be marginally greater than that of pure CMTC crystal.

\section{Conclusion}

$\mathrm{Co}^{2+}$ mixed CMTC crystal has been successfully synthesized and the crystals have been grown by slow evaporation method at $35^{\circ} \mathrm{C}$ in a constant temperature bath. The results of its characterization analyses were compared with that of pure CMTC single crystal. Single crystal $\mathrm{X}$-ray diffraction analysis showed that both the crystals belong to monoclinic system. Functional groups were analyzed by using FT-IR analysis, which has revealed the characteristic vibration modes of pure and $\mathrm{Co}^{2+}$ mixed CMTC crystals. UV cut-off wavelength of the $\mathrm{Co}^{2+}$ mixed CMTC grown crystal was found to be $245 \mathrm{~nm}$ which is better than the pure CMTC crystal. The TGA and DTA analysis under nitrogen atmosphere reveals that 
$\mathrm{Co}^{2+}$ mixed CMTC crystal has marginally better thermal stability than the pure CMTC crystal. But the second harmonic generation efficiency test by Kurtz-Perry powder technique reveals that both the crystals are inferior to that of standard potassium dihydrogen phosphate (KDP) crystal.

\section{Acknowledgements}

The authors are thankful to Prof. P. K. Das, IISC, Bangalore, India for the SHG test. They also express their gratitude to the authorities of SAIF, IIT, Chennai, India, ACIC, St. Joseph's College, Tirchirappalli, India and ICP, CECRI, Karaikudi, India for providing spectral facilities, to undertake this study. The authors are also thankful to Prof. M. Arulanandasamy, Department of English, AAMEC, Kovilvenni, for his careful revision and proof reading of the text at every stage of its preparation.

\section{REFERENCES}

[1] X. Q. Wang, et al., "Crystal Growth and Charecterization of a Novel Organometallic Nonlinear-Optical Crystal: $\mathrm{MnHg}(\mathrm{SCN})_{4}\left(\mathrm{C}_{2} \mathrm{H}_{6} \mathrm{OS}\right)_{2}$," Journal of Crystal Growth, Vol. 224, No. 3-4, 2001, pp. 284-293. doi:10.1016/S0022-0248(01)01012-0

[2] S. Gunasekaran and S. Ponnusamy, "Growth and Characterization of Cadmium Magnesium Tetra Thiocyanate Crystals," Crystal Research and Technology, Vol. 41, No. 2, 2006, pp. 130-137. doi:10.1002/crat.200510544

[3] C. R. Raja and B. Vijayabhaskaran, "Synthesis, Growth and Characterization of a New Non-Linear Optical Crystal: Copper Cobalt Thiocyanate," Indian Journal of Pure and Applied Physics, Vol. 49, 2011, pp. 531-534.

[4] P. Paramasivam and C. R. Raja, "Synthesis, Growth and Characterization of Cadmium Manganese Thiocyanate Crystal," Spectrochimica Acta Part A: Molecular and Biomolecular Spectroscopy, Vol. 79, No. 5, 2011, pp. 11091112. doi:10.1016/j.saa.2011.04.028

[5] P. N. S. Kumari and S. Kalainathan, "Comparative Study of Pure and Magnesium Doped Cadmium Mercury Thiocyanate Single Crystals-Gel Technique," Journal of Minerals \& Materials Characterization \& Engineering, Vol. 7, No. 4, 2008, pp. 317-330.
[6] G. P. Joseph, et al., "The Influence of Metallic Sustitution on the Physical Properties of Maganese Mercury Thiocyanate Crystals," Crystal Research and Technology, Vol. 42, No. 3, 2007, pp. 295-299. doi:10.1002/crat.200610816

[7] B. Vijayabhaskaran, M. Arivazhagan and C. R. Raja, "Synthesis, Growth and Characterization of Copper Mercury Thiocyanate Crystal," Indian Journal of Pure and Applied Physics, Vol. 49, 2011, pp. 340-343.

[8] C. M. Raghavan, et al., "Synthesis Growth and Charecterization of Nonlinear Optical Diaqua Manganese MercuryN, N-Dimethylacetamide Single Crystals," Journal of Crystal Growth, Vol. 311, No. 5, 2009, pp. 1346-1351. doi:10.1016/j.jcrysgro.2008.12.048

[9] X. Q. Wang, et al., "Growth and Characterization of a Novel UV Nonlinear Optical Crystal:

$\left[\mathrm{MnHg}(\mathrm{SCN})_{4}\left(\mathrm{H}_{2} \mathrm{O}\right)_{2}\right] \cdot 2 \mathrm{C}_{4} \mathrm{H}_{9} \mathrm{NO}$," Journal of Crystal Growth, Vol. 234, No. 2-3, 2002, pp. 469-479. doi:10.1016/S0022-0248(01)01731-6

[10] A. Sabatini and I. Bertini, "Infrared Spectra between 100 and $2500 \mathrm{Cm}^{-1}$ of Some Complex Cyanates, Thiocyanates and Selenocyanates," Inorganic Chemistry, Vol. 4, No. 7, 1965, pp. 959-961. doi:10.1021/ic50029a007

[11] X. Q. Wang, et al., "Preparation and Characterization of $\mathrm{Hg}\left(\mathrm{N}_{2} \mathrm{H}_{4} \mathrm{CS}\right)_{4} \mathrm{Zn}(\mathrm{SCN})_{4}$," Journal of Crystal Growth, Vol. 271, No. 1-2, 2004, pp. 120-127. doi:10.1016/j.jcrysgro.2004.07.045

[12] K. Selvaraju, R. Valluvan and S. Kumararaman, "A New Metal-Organic Crystal: Potassium Thiourea Chloride," Materials Letters, Vol. 61, No. 3, 2006, pp. 751-753. doi:10.1016/j.matlet.2006.05.054

[13] X. Q. Wang, et al., "Spectroscopic and Thermal Behavior of $\mathrm{ZnHg}(\mathrm{SCN})_{4}$," Materials Research Bulletin, Vol. 37, No. 11, 2002, pp. 1859-1871. doi:10.1016/S0025-5408(02)00859-0

[14] X. Q. Wang, et al., "Growth, Spectroscopic and Thermal Behavior of $\mathrm{Cd}(\mathrm{SCN})_{2}(\mathrm{DMSO})_{2}$," Journal of Crystal Growth, Vol. 246, No. 1-2, 2002, pp. 155-160. doi:10.1016/S0022-0248(02)01763-3

[15] S. K. Kurtz and T. T. Perry, "A Powder Technique for the Evaluation of Nonlinear Optical Materials," Journal of Applied Physics, Vol. 39, No. 8, 1968, pp. 3798-4013. doi:10.1063/1.1656857 